\title{
Colaborações e revisões da concepção de intervenção experimental com vistas à divulgação do projeto Insonia
}

\author{
Collaborations and reviews of the \\ experimental intervention design \\ with a view to disseminating \\ the Insonia project
}

Eduardo Mendes ${ }^{[1]}$, Nadia Miranda Leschko ${ }^{[2]}$

\begin{abstract}
Resumo: Este artigo apresenta os resultados e desdobramentos do trabalho de conclusão de curso de Design Gráfico da Universidade Federal de Pelotas, intitulado "Projeto Insonia: concepção de intervenção experimental com vistas a divulgação do projeto e comunicação entre os diferentes movimentos contraculturais", que foi orientado pela profa. Nadia Miranda Leschko e defendido no dia 17 de dezembro de 2019. O projeto teve como proposta criar uma intervenção experimental a fim de integrar diferentes movimentos contraculturais do cenário underground, com foco na cidade de Pelotas - RS inicialmente, servindo como um canal de comunicação para esses. Além de demonstrar o produto oriundo do processo, relato neste os primeiros testes após a execução, apontando possíveis melhorias para o projeto.
\end{abstract}

Palavras-chave: Intervenção. design thinking. Contracultura.

Abstract: This article presents the results and developments of the term paper of graphic design course at the Universidade Federal de Pelotas, entitled "Projeto Insonia: conception of experimental intervention with a view to disseminating the project and communication between different countercultural movements", which was guided by

[1] Bacharel em Design Gráfico, UFPEL. canalduapv@gmail.com

[2] Doutora em Design, PUC-RIO.nadia.ufpel@gmail.com 
professor Nadia Miranda Leschko and defended on December 17, 2019. The project had the proposal to create an experimental intervention in order to integrate different counter cultural movements from the underground scene, focusing on the city of Pelotas - RS initially, serving as a communication channel for those. In addition to demonstrating the product from the process, I report the first tests after the execution, pointing out possible improvements for the project.

Keywords: Intervention. Design thinking. Counterculture.

\section{INTRODUÇÃO}

Este artigo é derivado do trabalho de conclusão de curso de Design Gráfico do primeiro autor intitulado “Projeto Insonia: concepção de intervenção experimental com vistas a divulgação do projeto e comunicação entre os diferentes movimentos contraculturais", orientado pela profa. Nadia Miranda Leschko, defendido no dia 17 de dezembro de 2019, e aprovado pela banca examinadora composta pela profa. Ana Paula Cruz Penkala Dias e pelo prof. Rafael Peduzzi Gomes.

Neste artigo, relato como se deu o processo de concepção dessa intervenção, apresento os resultados da execução e dos primeiros testes, apontando melhorias necessárias para a realização dele.

O aporte teórico utilizado no trabalho de conclusão do curso foi baseado nas seguintes obras: o livro de Howard S. Becker, "Outsiders: Estudos da Sociologia do Desvio" (2009), que auxiliou na compreensão das ações transgressoras cometidas pelos movimentos destacados no projeto, além de compreender o público alcançado pelo mesmo; a tese de Capellari, "O discurso da contracultura no Brasil: o underground através de Luiz Carlos Maciel" (2007), que serviu para definir os movimentos destacados em âmbito nacional, como a contracultura, o movimento underground e suas respectivas características; a obra de Lassala, "Em nome do Pixo: A experiência social e estética do pixador e artista Djan Ivson" (2014), para entender a relação da expressão gráfica, especialmente o pixo, com os movimentos contraculturais; e também a obra de Ellen Lupton, "Intuição, Ação, Criação: Graphic Design Thinking" (2011) que inspirou a metodologia de projeto da intervenção. 
O artigo está estruturado da seguinte forma: no primeiro tópico, "sobre o projeto Insonia e metodologia utilizada para a concepção de intervenção", faço breve apresentação do projeto Insonia, abordo a metodologia utilizada e passo-a-passo da concepção de intervenção; no segundo tópico, "resultados", apresento os resultados do trabalho de conclusão de curso, no terceiro tópico, "considerações sobre o produto", analiso as colaborações e revisões coletadas pós-defesa, no quarto e último tópico, “Conclusão” faço as considerações finais sobre este artigo.

\section{SOBRE O PROJETO INSONIA E METODOLOGIA UTILIZADA PARA A CONCEPÇÃO DE INTERVENÇÃO}

O projeto Insonia[ ${ }^{[3]}$ nasceu como uma necessidade de identificar uma produção autoral e experimental na cidade de Pelotas-RS inicialmente, com o objetivo de representar a contracultura, uma vertente artístico-cultural presente na vida de Lucas Vieira, fotógrafo de São José dos Campos/SP e fundador do projeto e o primeiro autor, natural de São Paulo/SP. Atualmente, o projeto se encontra paralisado por conta da pandemia do Covid-19. A Insonia conta com dois integrantes, sendo um designer, o primeiro autor, e um fotógrafo, mas já produziu com músicos, cineastas, artistas, designers, fotógrafos e produtores culturais. Até então, toda a produção do projeto Insonia buscou realizar uma interação entre os diferentes movimentos culturais que flutua, e tem como ideia principal se aliar à produção cultural presente nas diversas facetas da cena underground, e se tornar um canal de comunicação entre essas diferentes vertentes desse meio.

A proposta do projeto Insonia é viabilizar um canal de comunicação entre diferentes movimentos contraculturais da cena underground, e foi idealizado neste trabalho como uma intervenção nos eventos realizados por esses.

Com a execução do projeto, foi concebida uma caixa de remédio chamada "Sispresse" que é utilizada para a proposta de intervenção. Dentro dessa caixa, há um pote, e no interior do mesmo, há diversas cápsulas com adesivos brancos e pin-
[3] O nome do projeto Insonia é originado da insônia, patologia referente à perda do sono. 
céis atômicos dentro. Para participar da intervenção, basta pegar o pincel atômico e se expressar da maneira que quiser no adesivo, podendo ser uma arte, uma tag ${ }^{[4]}$, uma mensagem, e depois pode colar no mural de exposição da intervenção. Nos próximos tópicos, esse produto será mais bem detalhado para compreensão da intervenção.

A pesquisa realizada no trabalho de conclusão de curso teve caráter exploratório, qualitativo e contou com análise de semeIhantes. A metodologia de projeto foi inspirada no modelo proposto por Ellen Lupton, em sua obra intitulada "Intuição, Ação, Criação: Graphic Design Thinking" (2011), e contou com 5 partes divididas em capítulos, sendo elas: "Sobre o projeto Insonia"; "Análise de semelhantes com foco em soluções experimentais"; "Processo de criação"; "Execução do projeto"; e "Conclusão".

O capítulo "Sobre o projeto Insonia" foi destinado a fornecer informações que ajudaram a dimensionar o referido projeto e, consequentemente, o produto gerado para ele. Neste capítulo também estão descritos os integrantes do projeto, como também a trajetória, as produções anteriores e quais os próximos passos do projeto.

No capítulo "Análise de semelhantes com foco em soluções experimentais" foi feita uma pesquisa acerca de outras marcas e projetos que se assemelhavam ao projeto Insonia de alguma forma, e analisei as soluções adotadas em cada situação, servindo de base para as próximas etapas do projeto. Foram analisadas 3 marcas, sendo elas a "Thrasher Magazine", a "MTV" e também a "Bolovo". Foram concebidos painéis semânticos para ilustrar o posicionamento da marca, como também um resumo identificando qual característica encontrada seria utilizada para auxiliar na produção do projeto Insonia. Esta etapa compreendeu a primeira parte da metodologia de projeto, a pesquisa.

O capítulo "Processo de criação" compreendeu o restante da metodologia de projeto adotada, separada em 5 partes: brainstorming; mapa mental; briefing de criação; brain dumping visual; mock-ups. Esse capítulo integrou a pesquisa com a geração de ideias, e contou com uma série de esboços que serviram de suporte para a execução do projeto (fig. 1).
[4] Marca de assinatura de um artista, geralmente utilizado por simpatizantes do graffiti. 


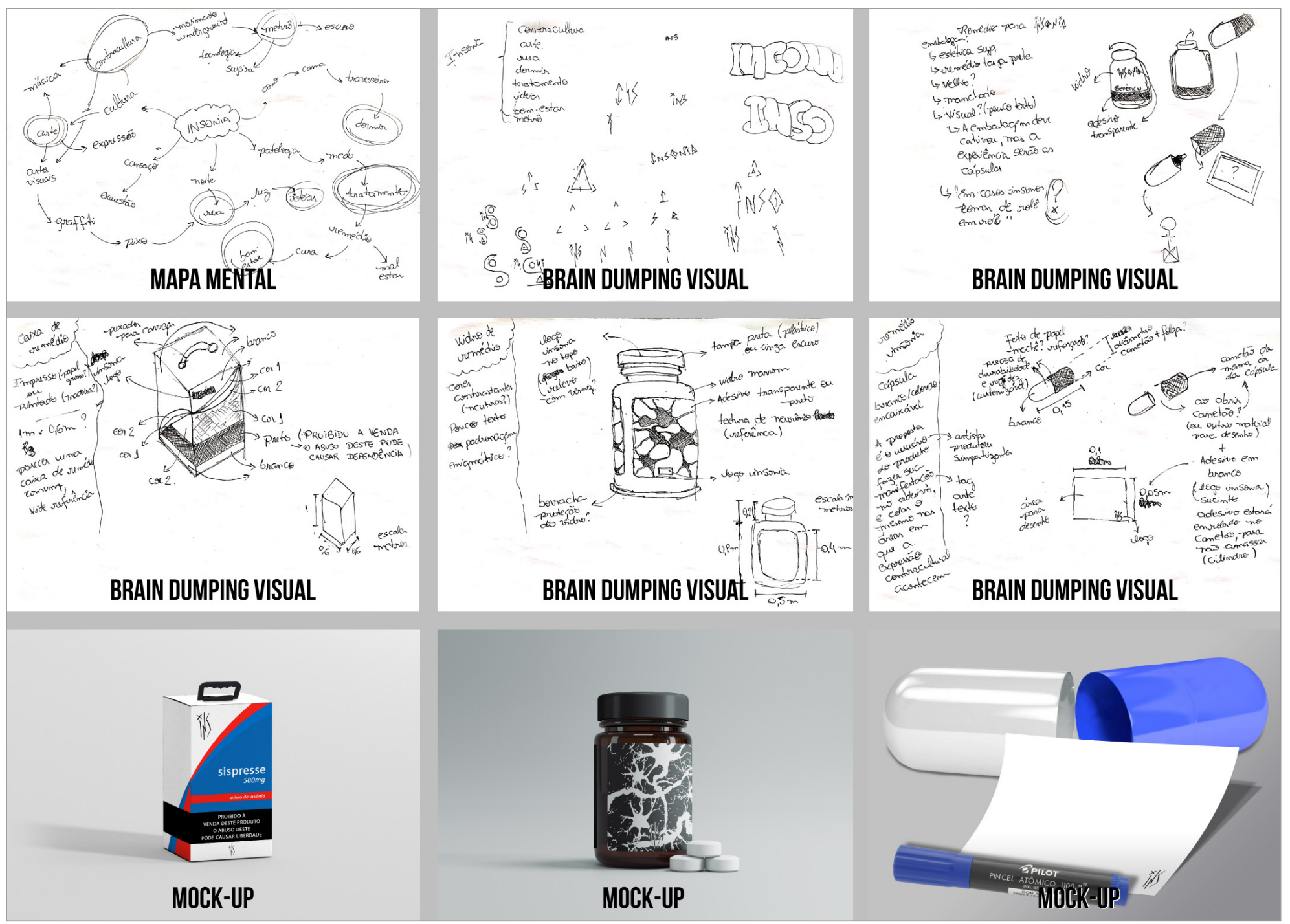

Figura 1 - Esboços do processo de criação. Fonte: desenvolvido pelo primeiro autor.

O capítulo "Execução do Projeto" compreendeu a produção das soluções propostas no capítulo anterior, relatando os processos de cada etapa, as alterações e os motivos que levaram a essas, explicando passo a passo como foi construído o produto que viabiliza a intervenção do projeto Insonia.

Por fim, no capítulo "conclusão", retomei o processo, os pontos positivos e negativos que identifiquei durante a concepção, como me senti após o término do projeto, o que ele agregou para mim, e comentei sobre os próximos passos do projeto. 


\section{RESULTADOS}

Durante a execução, algumas alterações foram feitas no projeto original visando sanar problemas que não foram encontrados nas etapas anteriores do processo, que inviabilizariam a produção, e consequentemente a intervenção. Conforme estes foram identificados, soluções foram adotadas visando tornar o processo mais prático e melhorar a qualidade do produto, como mudar o material da embalagem, como também alterar o mecanismo de transporte e abertura, além de outros (fig. 2).
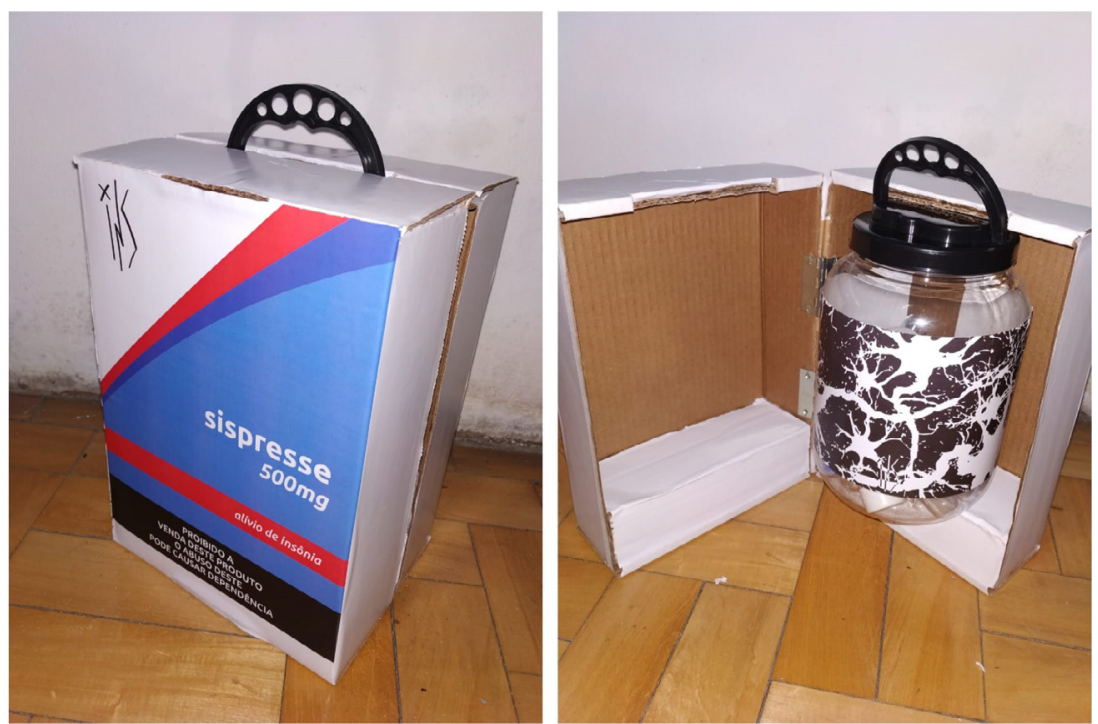

Figura 2 - Resultado do projeto de intervenção. Fonte: desenvolvido pelo primeiro autor
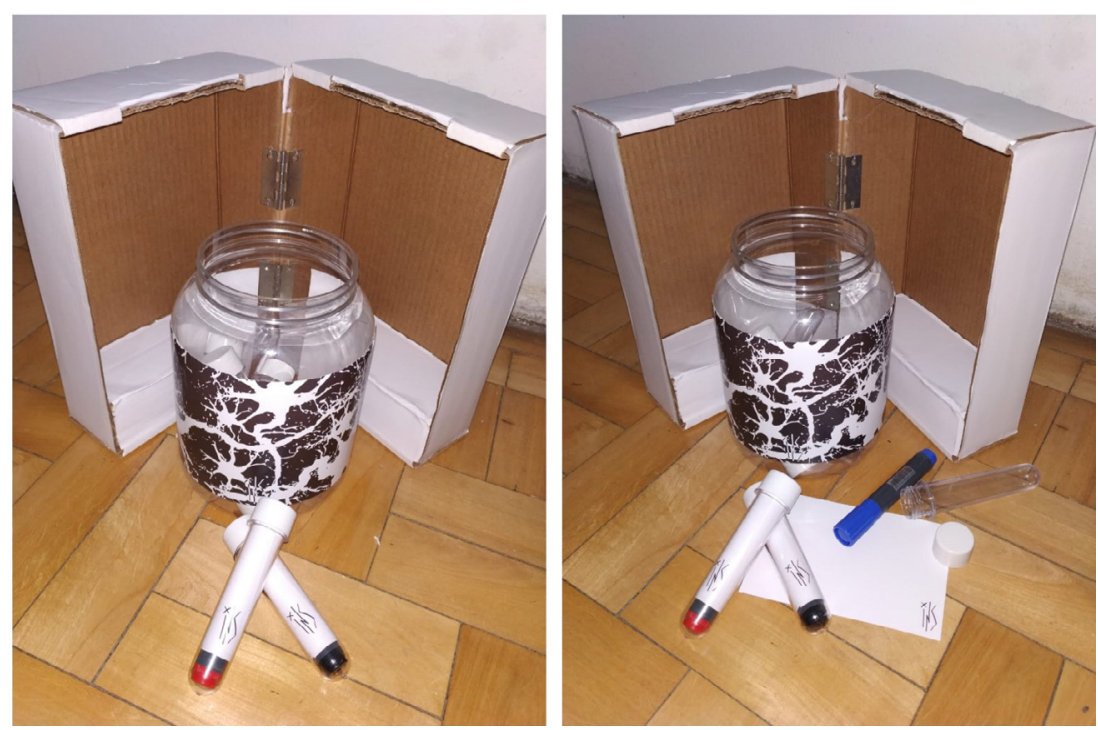


\section{CONSIDERAÇÕES SOBRE O PRODUTO APÓS A DEFESA}

Com o resultado do projeto, comecei a fazer testes com o intuito de realizar as intervenções, segundo a proposta dele. Para tanto, contei com opiniões de artistas e produtores envolvidos com a cena underground em Pelotas - RS, e, após essa testagem, cheguei a 3 pontos que podem ser repensados antes da intervenção ser realizada, sendo eles:

\section{a) 0 produto desenvolvido não ficou tão intuitivo como pla-} nejado. Os produtores, ao entrarem em contato com o projeto, não souberam intuitivamente o que fazer para participar da ação planejada. Após uma breve instrução verbal informando que eles poderiam mexer e interagir da maneira que quisessem com o objeto, o teste aconteceu de maneira mais fluída. Eles entenderam que poderiam se apropriar do que estava dentro da cápsula e poderiam se expressar como quisessem. Pensando nisso, identifiquei que preciso idealizar uma forma de instruir os consumidores da intervenção, podendo ser através de uma peça de apoio como um cartaz, ou até mesmo cada embalagem ilustrar os passos para sua utilização dentro da área vazia da mesma, se houver, ou até repensar a embalagem se for o caso. Como a intervenção é pensada visando alocar um espaço pré-determinado dentro de um evento, as duas opções são viáveis e podem ser aplicadas, inclusive, simultaneamente.

\section{b) A intervenção não foi pensada para ser utilizada no es-} curo. Os pincéis atômicos utilizados não interagem bem com a falta de luz geralmente encontrada nos eventos que a intervenção vai ocorrer, visto que não são materiais próprios para este ambiente. Sendo assim, é necessário pensar um esquema de luzes portátil e prático para instalar nas intervenções e assim viabilizar uma melhor interação do público com o projeto, com uma iluminação focada para não agredir a estética do resto do espaço. Outra opção seria pensar em materiais que sejam fotossensíveis, visto que alterar a iluminação do espaço talvez não seja uma opção viável por possíveis conflitos com os organiza- 
dores do evento. A primeira opção é a mais viável por adicionar alguns elementos no projeto, e não reformular o projeto em si, entretanto continuarei avaliando possíveis soluções para este problema a fim de evitar quaisquer complicações no futuro.

c) A maior embalagem da peça, a caixa, tem um mecanismo de abertura lateral, e o mesmo não é prático para o projeto. Com a realização dos testes, dois problemas com a abertura lateral da caixa ficaram evidentes, sendo o primeiro deles, a falta de estrutura para que a mesma se mantenha estática após aberta, visto que o ato de pegar o pote de plástico e o colocar de volta, desestabiliza a caixa e por vezes a fez cair. O segundo é a quebra da visualidade do projeto, visto que todas as embalagens foram pensadas para cativar o público que estiver presente no evento, que o mesmo tenha sua atenção desviada para as embalagens, e se sinta intrigado e motivado a participar da intervenção. Porém, a abertura lateral da caixa não se mantém apresentável durante a utilização do projeto. Deverá ser reavaliada uma abertura na parte superior da caixa, adaptando a alça para transporte, ou até uma abertura na parte inferior da caixa, atrelado a algum mecanismo com trava para permitir a locomoção dela.

\section{CONCLUSÃO}

Este artigo teve como objetivo apresentar os resultados e desdobramentos do projeto "Projeto Insonia: concepção de intervenção experimental com vistas a divulgação do projeto e comunicação entre os diferentes movimentos contraculturais".

Devido a pandemia do COVID-19, não foi possível realizar a intervenção do projeto para avaliar se seu objetivo seria atingindo como o proposto, sendo postergado para quando esta situação for normalizada. Entretanto, com os testes realizados pude perceber alguns pontos que podem ser reavaliados antes de uma execução da intervenção, visando afetar positivamente no efeito causado pelo projeto. 
Encerro este artigo apresentando o próximo passo do projeto Insonia, que é o de servir como um canal de comunicação, idealizado, a princípio, como uma revista impressa. Para tal, irei realizar as intervenções provenientes deste e agregar colaboradores para viabilizar a nova etapa do projeto.

\section{REFERÊNCIAS BIBLIOGRÁFICAS}

BECKER, Howard Saul. Outsiders: Estudos de sociologia do Desvio. Rio de Janeiro: Zahar, 2009.

CAPELLARI, Marcos Alexandre. $\mathbf{O}$ discurso da contracultura no Brasil: o underground através de Luiz Carlos Maciel. São Paulo: USP, 2007. Tese, Pós-Graduação em História, Faculdade de História, Universidade de São Paulo, 2007.

LASSALA, Gustavo. Em nome do Pixo: A experiência social e estética do pixador e artista Djan Ivson. São Paulo, Mackenzie, 2014. Tese, Pós-Graduação em Arquitetura e Urbanismo, Faculdade de Arquitetura e Urbanismo, Universidade Presbiteriana Mackenzie, 2014.

LUPTON, Ellen. Intuição, ação, criação:

Graphic Design Thinking. tradução Mariana

Bandarra - São Paulo: Editora G. Gili, 2011. 